\title{
IMPLEMENTASI PERATURAN MENTERI HUKUM DAN HAK ASASI MANUSIA NOMOR 27 TAHUN 2016 TENTANG FORMASI JABATAN NOTARIS DAN PENENTUAN KATEGORI DAERAH TERHADAP PENEMPATAN NOTARIS KEPULAUAN RIAU
}

\author{
Ampuan Situmeang* \\ Luthfi Muhammad Fajar* \\ Program Magister Hukum, Fakultas Hukum UIB
}

\begin{abstract}
Batam City is one of the fastest growing cities with an economic growth that exceeds the national average economic growth. By seeing the high economic growth in Batam City, of course, it is very necessary to have a notary as a general official. In the Regulation of the Minister of Law and Human Rights of the Republic of Indonesia Number 27 of 2016 concerning Formation of Notary Positions and Determination of Regional Categories regulates the placement of Notaries based on quotas and regional categories, so that new or already assigned Notaries cannot directly choose their place of domicile because it is based on a quota set. The Minister of Law and Human Rights of the Republic of Indonesia has made a regulation regarding the formation of a Notary office, where in the regulation, Notary Candidates cannot submit applications to Category A, B and C Regions. For Notary Candidates, the formation of Notary positions that can be proposed is only for Category Region D. After carrying out notary duties in Category D for a minimum of three years, the Notary is given the right to apply for a transfer of the work area to Category $C$. Notary candidates must first carry out their duties in the Category $D$ work area.
\end{abstract}

Keywords: Batam City Notary, RI Minister of Law \& Human Rights Regulation, City Batam, Placement of Notaries.

\begin{abstract}
Abstrak
Kota Batam merupakan salah satu kota yang berkembang dengan pesat dengan pertumbuhan ekonomi yang melebihi dari rata-rata pertumbuhan ekonomi secara nasional. Melihat begitu tingginya pertumbuhan ekonomi di Kota Batam, tentunya sangat diperlukan keberadaan Notaris selaku pejabat umum. Dalam Peraturan Menteri Hukum dan Hak Asasi Manusia Republik Indonesia Nomor 27 Tahun 2016 tentang Formasi Jabatan Notaris dan Penentuan Kategori Daerah mengatur tentang penempatan Notaris berdasarkan kuota dan kategori daerah, sehingga Notaris baru maupun yang telah bertugas tidak dapat secara langsung memilih tempat kedudukannya karena berdasarkan kuota yang ditetapkan. Menteri Hukum dan Hak Asasi Manusia Republik Indonesia telah membuat regulasi mengenai formasi jabatan Notaris, dimana di dalam peraturan tersebut, Calon Notaris tidak bisa mengajukan permohonan ke Kategori Daerah A, B dan C. Bagi Calon Notaris, formasi jabatan Notaris yang dapat diusulkan hanya untuk Kategori Daerah D.
\end{abstract}

\footnotetext{
*Alamat Korespondensi : ampuan.situmeang@gmail.com

*Alamat Korespondensi : agencykepri@gmail.com
} 
Setelah melaksanakan tugas kenotariatan di Kategori Daerah D selama minimal tiga tahun, Notaris diberikan hak untuk mengajukan permohonan perpindahan wilayah kerja ke Kategori Daerah C. Calon Notaris harus melaksanakan tugas di wilayah kerja Kategori D terlebih dahulu.

Kata Kunci : Notaris Kota Batam, Peraturan Menteri Hukum \& HAM RI, Kota Batam, Penempatan Notaris.

\section{A. Latar Belakang Masalah}

Dengan tujuan agar masyarakat mendapatkan kepastian hukum, yang diantaranya adalah bidang hukum perdata, pemerintah telah mengeluarkan aturanaturan yang mengatur tentang pentingnya proses pengesahan dalam setiap kegiatan di masyarakat. Prinsip negara hukum menjamin kepastian, ketertiban, dan perlindungan hukum yang berintikan kebenaran dan keadilan. Kehadiran notaris sebagai pejabat publik merupakan bentuk dari kepastian hukum atas setiap perbuatan, perjanjian, penetapan, dan peristiwa hukum. Pengesahan tersebut dilakukan oleh pemangku jabatan yang diberikan wewenang, atau masyarakat yang ditunjuk sebagai pemangku jabatan dan diatur oleh undang-undang.

Profesi notaris yang secara fungsional berperan dalam kehidupan masyarakat sampai saat ini tetap masih terasa disegani. Selain dianggap sebagai seorang pejabat, notaris biasanya juga dianggap sebagai seseorang yang dapat memberikan nasihat-nasihat dan saran-saran yang sangat dapat dijadikan acuan. ${ }^{1}$ Semua hal yang ditulisnya, dan juga yang ditetapkan atau dikonstatir merupakan halhal yang dianggap benar, dan seorang notaris dianggap sebagai pembuat dokumen yang dianggap memiliki kedudukan yang kuat didalam sebuah proses hukum. ${ }^{2}$

Sangat tidak mudah untuk menentukan formasi atau jumlah notaris yang dibutuhkan untuk setiap kota atau kabupaten, harus ada parameter atau alasan yang terukur mengenai formasi notaris untuk tiap kota atau kabupaten tersebut. Pasal 22 Ayat (1) UU No. 2 Tahun 2014 ditegaskan bahwa formasi jabatan notaris ditetapkan berdasarkan : Kegiatan dunia usaha; Jumlah penduduk dan/atau; Ratarata jumlah akta yang dibuat oleh dan/atau dihadapan notaris setiap bulan.

Saat ini terdapat 120 orang Notaris yang tersebar di Kota Batam. Dalam Permenkumham RI Nomor 27 Tahun 2016 tentang Formasi Jabatan Notaris dan Penentuan Kategori Daerah mengatur tentang penempatan Notaris berdasarkan kuota dan kategori daerah, sehingga Notaris baru maupun yang telah bertugas tidak dapat secara langsung memilih tempat kedudukanny. Notaris di Kota Batam telah mencapai jumlah 120 orang, namun permintaan penempatan Notaris di Kota Batam terus meningkat sehingga perlu dikaji lebih dalam mengapa Notaris-notaris tersebut menginginkan Kota Batam sebagai kedudukannya.

Sesuai dengan penjelasan tersebut, penulis merasa tertarik dan menganggap perlu dilakukan penelitian, dengan judul penelitian: "Implementasi Peraturan Menteri Hukum dan Hak Asasi Manusia Republik Indonesia Nomor 27 Tahun 2016

\footnotetext{
${ }^{1}$ Abdul Ghofur Anshori, Lembaga Kenotariatan Indonesia, Yogyakarta, UII Press, 2009, hlm. 11.

${ }^{2}$ Tan Thong Kie, Studi Notariat dan Serba-Serbi Praktek Notaris, Cetakan Kedua, Jakarta:

PT. Ichtiar Baru van Hoeve., 2011, hlm. 444.
} 
Tentang Formasi Jabatan Notaris dan Penentuan Kategori Daerah terhadap penempatan Notaris Kepulauan Riau di Kota Batam."

\section{B. Perumusan Masalah}

Berdasarkan uraian latar belakang penelitian diatas, permasalahannya adalah sebagai berikut:

1. Bagaimanakah formasi pengangkatan Notaris dibatasi dalam Permenkumham Nomor 27 Tahun 2016?

2. Bagaimanakah implementasi penentuan kategori daerah dalam penentuan daerah Notaris di Kota Batam?

\section{Metode Penelitian}

Dalam penelitian ini peneliti menggunakan Hukum sosiologi atau empiris. Menurut Bambang Sunggono dalam bukunya menyatakan bahwa "Penelitian Hukum sosiologis atau empiris hendak mengadakan pengukuran terhadap peraturan perundang-undangan tertentu mengenai efektivitasnya, maka defenisi-defenisi operasional dapat diambil dari peraturan perundangundangan tersebut. Sisi lainnya secara historis, pemanfaatan untuk lebih efektif menyelesaikan masalah-masalah sosial dikembangkan dalam rangka ajaran sociological jurisprudence, yang dalam perkembangannya dalam rangka kajian sociology of law dimanfaatkan untuk menganalisis dan memberikan jawaban untuk mengefektifkan bekerjanya seluruh struktur institusional hukum". 3

Objek Penelitian yang penulis gunakan adalah data sekunder dan data primer, data utama penulis adalah data primer berupa wawancata dan obersevasi, sedangkan data sekunder yang penulis gunakan adalah sebagai berikut:

1) Bahan Hukum Primer

Bahan hukum primer, adalah bahan-bahan hukum yang mengikat yang terdiri dari peraturan perundang-undangan yang relevan dengan permasalahan. Bahan hukum primer dalam penelitian ini berasal dari peraturan perundang-undangan yang berkaitan dengan penelitian hukum yang dilakukan.

2) Bahan Hukum Sekunder

Bahan hukum sekunder, adalah bahan-bahan penjelasan dari bahan hukum primer. Bahan hukum sekunder dalam penelitian ini berupa buku-buku, makalah, majalah, jurnal, dan bahan lainnya yang memiliki keterkaitan dengan obyek penelitian.

Teknik pengumpulan data yang peneliti yang peneliti lakukan dengan menggunakan Alat pengumpulan data seperti wawancara (Interview). Pengolahan dan Analisis data pada penelitian hukum sosiologis, tunduk pada cara analisis data ilmu-ilmu sosial. Untuk menganalisis data, tergantung pada sifat data yang dikumpulkan oleh peneliti (tahap pengumpulan data). Metode

\footnotetext{
${ }^{3}$ Wordpress, "Pengertian Penelitian Menurut Ahli", https://metodepenelitianhlw134a09.wordpress.com/2016/03/30/12-pengertian-penelitian-menurutpara-ahli-lengkap/, diakses pada 22 Agustus tahun 2019.
} 
analisa data yang digunakan dalam penelitian ini adalah menggunakan metode pendekatan kualitatif, yaitu suatu pembahasan yang dilakukan dengan cara memadukan antara penelitian kepustakaan dan penelitian lapangan. Penelitian kepustakaan yang dilakukan adalah membandingkan peraturan-peraturan, ketentuan-ketentuan, dan buku referensi, serta data yang diperoleh, kemudian dianalisis secara kualitatif yang akan memberikan gambaran menyeluruh tentang aspek hukum yang berhubungan dengan masalah yang akan diteliti. ${ }^{4}$

Data yang diperoleh dalam penelitian ini dianalisis secara yuridis kualitatif dengan menggunakan metode berpikir deduktif (umum-khusus), yaitu dengan menjabarkan, menafsirkan dan mengkonstruksikan data yang diperoleh berdasarkan norma-norma atau kaidah-kaidah, teori-teori, pengertian-pengertian hukum dan doktrin-doktrin yang ada dalam dokumen, Peraturan Perundang-undangan, untuk menjawab permasalahan yang ada. Analisis data dilakukan secara bertahap, sehingga kekurangan data penelitian secepatnya dapat diketahui dan sesegera mungkin dilengkapi dengan melakukan penelitian ulang guna pengambilan data tambahan untuk melengkapi kekuarangan data tersebut.

Analisis mengenai permasalahan yang diangkat dalam penelitian ini, dilakukan dengan cara menganalisis permasalahan yang ada di lapangan yakni mengenai formasi notaris di Kota Batam, selanjutnya akan dikaji dengan dikaitkan dengan peraturan perundang-undangan yang berlaku yaitu Undang-Undang Republik Indonesia Nomor 30 Tahun 2004 tentang Jabatan Notaris, dan peraturan perundang-undangan lainnya yang memiliki keterkaitan dengan Formasi Jabatan Notaris dan Penentuan Kategori Daerah.

Setelah analisis selesai, maka hasilnya akan disajikan secara narasi deskriptif, yaitu dengan cara menguraikan temuan dilapangan sesuai dengan permasalahan yang diteliti. Kemudian ditarik kesimpulan yang merupakan jawaban atas permasalahan yang diangkat dalam penelitian ini.

\section{Hasil Penelitian dan Pembahasan}

\section{1) Hasil Penelitian:}

\section{Hasil Wawancara :}

Para pihak yang terlibat dalam proses penempatan dan pengangkatan Notaris berjumlah 4 (empat) orang. Orang tersebut berasal dari unsur pemerintahan, Notaris dan Organisasi Ikatan Notaris Indonesia (INI). Adapun hasil wawancara tersebut diuraikan dibawah ini:

a. Andi Yulia Hertaty, S.H., M.Kn., berusia 42 tahun dan berprofesi sebagai Pegawai Negeri Sipil, dengan jabatan sebagai Kepala Seksi Pengangkatan dan Perpindahan Notaris pada Sub Direktorat Notariat, Direktorat perdata Direktorat Jenderal Administrasi Hukum Umum, Kementerian Hukum dan Hak Asasi Manusia Republik Indonesia di Jakarta menjelaskan bahwa saat ini terdapat 42 Perguruan Tinggi Negeri dan Swasta yang memiliki Program Studi Magister

\footnotetext{
${ }^{4}$ Amiruddin, Pengantar Metode Penelitian Hukum, Jakarta: PT. Raja Grafindo, 2010.
} 
Kenotariatan. Pada tahun 2016, terdapat 1.520 permohonan pengangkatan Notaris dan pada tahun 2017 terdapat 1.200 permohonan pengangkatan Notaris. Pada tahun 2017 bulan september sudah diterapkan kategori daerah diseluruh Indonesia. Saat ini terdapat 17.319 Notaris diseluruh Indonesia, jumlah tersebut belum dikurangi dengan Notaris yang pensiun dan mengundurkan diri sejumlah 1.444 orang. Kemudian Notaris yang belum aktif sejumlah 83 Orang yang belum melaporkan kepada Kementerian Hukum dan Hak Asasi Manusia Republik Indonesia setelah dilantik. Calon Notaris yang mengajukan permohonan sebanyak 2.142 calon Notaris dan harus memiliki sertifikat magang yang dikeluarkan oleh organisasi Ikatan Notaris Indonesia untuk mengikuti Ujian Pengangkatan Notaris. Bagi Calon Notaris yang mengharapkan mendapatkan formasi wilayah kerja di Kota Batam harus mengisi formasi di Kategori Daerah D terlebih dahulu, karena Kota Batam masuk dalam Kategori Daerah C.

b. Syaifudin, S.H, berusia 58 Tahun, berprofesi sebagai Notaris, dengan jabatan sebagai Ketua Pengurus Wilayah Ikatan Notaris Indonesia Provinsi Kepulauan Riau dan berkantor di Kota Batam dengan wilayah kerja Provinsi Kepulauan Riau. Menjelaskan bahwa, untuk bisa menjadi Notaris, seseorang tersebut harus memiliki keterampilan dan pendidikan Magister Kenotariatan. Setelah menyelesaikan program pendidikan Magister Kenotariatan, para calon Notaris tersebut harus melakukan magang di Kantor Notaris selama dua tahun. Untuk bisa bertugas di Kota Batam, Notaris yang baru harus terlebih dahulu melaksanakan tugas-tugas kenotariatan di wilayah yang tidak termasuk dalam Formasi Daerah A, B dan C, karena Notaris baru hanya bisa memilih Formasi Daerah D.

c. Nani Fitriyah, S.H., M.Kn, berusia 42 tahun, berprofesi sebagai Notaris, dengan jabatan sebagai Ketua Majelis Pengawas Daerah Notaris Kota Batam dan berkantor di Kota Batam dengan wilayah kerja Provinsi Kepulauan Riau mengatakan bahwa pada saat ini di Kota Batam telah terdapat 120 orang Notaris yang tersebar diseluruh Kota Batam. Jumlah tersebut belum dikurangi oleh Notaris yang meninggal dan pindah. Menurut aplikasi AHU Online, saat ini terdapat 30 formasi penempatan Notaris di Kota Batam, sehingga Notaris-notaris baru ataupun Notaris yang ingin mengajukan pindah ke Kota Batam dapat mengajukannya melalui Majelis Pengawas Notaris sesuai kedudukannya.

d. Adriosa, S.H., M.Kn, berusia 34 Tahun, berprofesi sebagai Notaris Kota Tanjungbalai Karimun, berkedudukan di Kota Tanjungbalai Karimun dan wilayah kerja Provinsi Kepulauan Riau. Beliau menjelaskan bahwa untuk menjadi seorang Notaris di Kepulauan Riau, harus memantau dan memperbarui informasi terkait kuota penempatan di daerah dengan kategori khusus seperti kateori D untuk Kota Tanjungbalai Karimun. Meskipun berdomisili di Kota Batam, belum tentu bisa memilih penempatan di Kota Batam karena terbentur dengan 
kategori daerah Kota Batam yang berkategori C. Seorang calon Notaris harus memulai penempatan pada kategori $\mathrm{D}$ dan dapat pindah ke kategori $\mathrm{C}$ bila telah menjalankan jabatannya selama tiga tahun dan telah mengerjakan seratus akta pada kantor Notarisnya. Saat ini beliau sudah menjalani selama tiga tahun masa jabatannya sebagai Notaris di Kabupaten Karimun dan saat ini sedang dalam proses pengajuan pindah wilayah kerja ke Kota Batam. Menurut beliau, formasi jabatan Notaris yang tersedia di Kota Batam sebanyak 30 orang. Informasi tersebut bisa didapat dari situs ahu online.

\section{Hasil Penelitian Pustaka/Studi Dokumen}

\section{a. Sejarah dan Perkembangan Notaris di Indonesia}

Atas dasar asas konkordansi maka lahirlah peraturan jabatan notaris di Indonesia mengalami perubahan yang sebelum ada perubahan lain terakhir dengan undang-undang tentang wakil notaris dan wakil notaris sementara undang-undang tanggal 13 november 1945, nomor 33 lembaran Negara 954 nomor 101 dan mulai berlaku tanggal 20 november 1954. Peraturan jabatan notaris yang berlaku sejak tahun 1860 sampai 2004 sangat dipengaruhi oleh peraturan notaris di Belanda (Notariswet) yang merupakan pengembangan dari peraturan notaris di Perancis (Ventosewet).

\section{b. Pengangkatan Notaris}

Setelah syarat-syarat terpenuhi maka notaris harus menjalankan tata cara yang telah ditetapkan oleh Kementerian Hukum dan Hak Asasi Manusia dalam Pasal 5 untuk mengisi format permohonan diangkat menjadi notaris yang diajukan kepada Menteri dan hanya memilih 1 (satu) tempat kedudukan di kabupaten/kota. ${ }^{5}$

Saat ini permohonan pengangkatan notaris dilakukan melalui sistem yang telah dirancang oleh Direktorat Jenderal Administrasi Hukum Umum Kementerian Hukum dan Hak Asasi Manusia Republik Indonesia, yaitu dengan cara online. Sehingga calon notaris dapat mengajukan permohonan pengangkatan notaris dengan mengakses http://ahu.go.id/. Calon notaris wajib mengisi semua data-data yang diminta dengan disertai dokumen pendukung.

\section{Tempat Kedudukan Jabatan Notaris}

Tempat kedudukan notaris diatur dalam Bab IV bagian pertama pasal 18 UUJN No. 30 Tahun 2004 jo UUJN No. 2 Tahun 2014 yang menjelaskan Kebutuhan notaris pada satu daerah kabupaten atau kota akan disesuaikan dengan formasi yang ditentukan pada daerah kabupaten atau kota berdasarkan keputusan menteri (Pasal 22 UUJN No. 30 Tahun 2004 jo UUJN No. 2 Tahun 2014). Formasi jabatan notaris yang dimaksud ditetapkan berdasarkan kegiatan dunia usaha, jumlah penduduk dan rata-rata jumlah akta yang dibuat oleh dan/atau di hadapan notaris setiap bulan.

\footnotetext{
${ }^{5}$ Soetarjo Soemoatmodjo, Apakah Notaris, PPAT, Pejabat Lelang, Yogyakarta, Liberty, 1986
} 
Ketentuan notaris mengenai tempat kedudukan jabatan notaris yang diatur dalam UUJN No. 30 Tahun 2004 jo UUJN No. 2 Tahun 2014 memiliki aturan yang dimana walaupun notaris dipandang sebagai jabatan yang bebas tetapi memiliki batasan. Bahwa pada tempat kedudukan notaris yang dimaksud disini ialah notaris wajib membuka hanya 1 (satu) kantor di daerah kabupaten atau kota kedudukan notaris dalam pasal 19 UUJN No. 30 Tahun 2004 jo UUJN No. 2 Tahun 2014. Pasal ini menerangkan bahwa Notaris dalam tempat kedudukannya harus memiliki satu kantor saja dan tidak berwenang secara berturut-turut menjalankan jabatannya di luar tempat kedudukannya.

\section{2) Pembahasan}

1. Formasi pengangkatan Notaris menurut Permenkumham Nomor 27 Tahun 2016

Presiden dalam menjalankan pemerintahannya dibantu oleh Menteri. Hal tersebut ditegaskan di Pasal 17 UUD Tahun 1945. Dalam menjalankan tersebut Menteri diberi kewenangan untuk mengeluarkan Peraturan Menteri. Dalam konteks eksistensi Peraturan Menteri di Indonesia

Terdapat dua syarat agar peraturan-peraturan sebagaimana dimaksud dalam Pasal 8 ayat (1) UU 12/ 2011 memiliki kekuatan mengikat sebagai peraturan perundangundangan, yaitu :

a. diperintahkan oleh peraturan perundang-undangan yang lebih tinggi; atau

b. dibentuk berdasarkan kewenangan.

Menurut HAS Natabaya, "pada dasarnya menteri sebagai pejabat negara didirinya melekat tiga kewenangan untuk membuat keputusan, yaitu keputusan, bersifat penetapan."6

Selanjutnya, Pasal 21 menyatakan jika Menteri berwenang menentukan Formasi Jabatan Notari. Kemudian pada Pasal 22 disebutkan bahwa :

1. Formasi Jabatan Notaris ditetapkan berdasarkan:

a. "Kegiatan dunia usaha;"

b. "Jumlah penduduk; dan/atau;"

c. "rata-rata jumlah Akta yang dibuat oleh dan/atau di hadapan Notaris setiap bulan."

Menindaklanjuti amanat dari undang-undang tersebut, Menkumham RI membuat suatu regulasi yang mengatur Kategori Daerah terdiri atas:

a. Kategori Daerah A meliputi:

1. Kota Administrasi Jakarta Selatan;

2. Kota Administrasi Jakarta Barat;

3. Kota Administrasi Jakarta Pusat;

4. Kota Administrasi Jakarta Utara; dan

5. Kota Administrasi Jakarta Timur.

b. Kategori Daerah B meliputi:

6 H.A.S. Natabaya, Sistem Peraturan Perundang-Undangan Indonesia, Sekjend Mahkamah Konstitusi, Jakarta, 2006, hlm. 177 


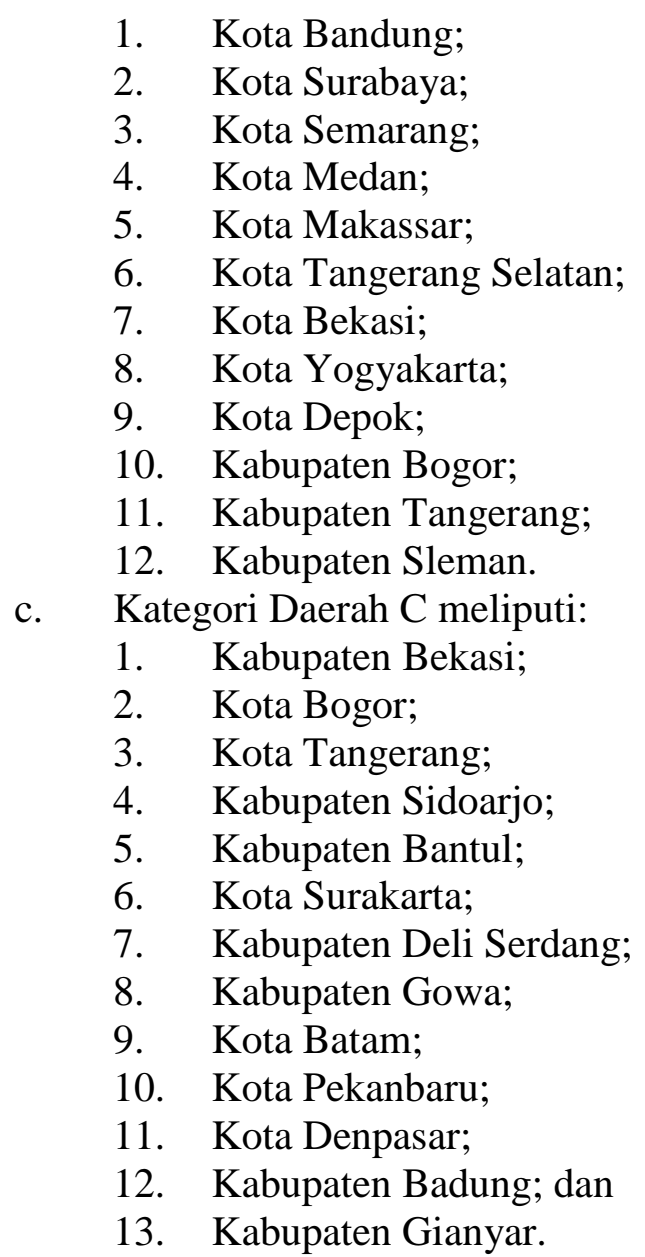

2. Implementasi Peraturan Menteri Hukum dan Hak Manusia Republik Indonesia Nomor 27 Tahun 2016 Tentang Formasi Jabatan Notaris dan Penentuan Kategori Daerah terhadap penempatan Notaris di Kota Batam

Batam merupakan wilayah strategis karena berada di sisi Selat Malaka. Kota Batam merupakan salah satu kota yang berkembang dengan pesat dengan pertumbuhan ekonomi yang melebihi dari rata-rata pertumbuhan ekonomi secara nasional. Hal ini didukung dengan perekonomian di kota Batam yang mayoritas didukung dari sektor perdagangan dan industri. Selain itu pertumbuhan sektor pariwisata juga berkembang dengan cepat pada beberapa tahun terakhir ini.

Namun demikian sektor industri tetap menjadi andalan yang utama. Kota Batam dikenal sebagai salah satu kota dengan kawasan industri terpadu di Indonesia. Sebagai salah satu daerah yang strategis sudah saatnya Batam memiliki ciri khas dalam bidang industrinya. Saat ini industri di kota ini sebagian besar ada pada sektor perkapalan dan elektronik.

Melihat begitu tingginya pertumbuhan ekonomi di Kota Batam, tentunya sangat diperlukan keberadaan Notaris selaku pejabat umum untuk mendukung perputaran roda ekonomi di Kota Batam dari sisi legalitas. Hal 
ini lah yang kemudian membuat tingginya animo calon notaris untuk dapat bekerja di kota Batam, karena banyaknya sektor-sektor usaha yang membutuhkan jasa seorang Notaris sebagai pejabat publik.

Saat ini terdapat 120 orang Notaris yang tersebar di Kota Batam. Dalam Permenkumham RI Nomor 27 Tahun 2016, penempatan Notaris berdasarkan kuota dan kategori daerah, sehingga Notaris baru maupun yang telah bertugas tidak dapat secara langsung memilih tempat kedudukannya karena berdasarkan kuota yang ditetapkan oleh Menkumham RI. Sekarang jumlah Notaris di Kota Batam telah mencapai jumlah 120 orang, namun permintaan penempatan Notaris di Kota Batam terus meningkat. ${ }^{7}$

Tingginya keinginan calon Notaris untuk bertugas di Kota Batam ternyata terbentur dengan katentuan yang terdapat pada Peraturan Menteri Hukum dan Hak Asasi Manusia Republik Indonesia Nomor 27 Tahun 2016 tentang Formasi Jabatan Notaris dan Penentuan Kategori Daerah. Dimana di dalam peraturan tersebut, Kota Batam masuk dalam Kategori Daerah C. Menkumham RI telah membuat regulasi mengenai formasi jabatan Notaris, dimana di dalam peraturan tersebut, Calon Notaris tidak bisa mengajukan permohonan ke Kategori Daerah A, B dan C. Bagi Calon Notaris, formasi jabatan Notaris yang dapat diusulkan hanya untuk Kategori Daerah D. Setelah melaksanakan tugas kenotariatan di Kategori Daerah D selama minimal tiga tahun, Notaris diberikan hak untuk mengajukan permohonan perpindahan wilayah kerja ke Kategori Daerah C. Sehingga Calon Notaris tidak bisa mengajukan permohonan wilayah kerja di Kota Batam karena Kota Batam termasuk dalam Kategori Daerah C. Calon Notaris harus melaksanakan tugas di wilayah kerja Kategori D terlebih dahulu, untuk kemudian apabila telah memenuhi persyaratan yang ditentukan dapat mengajukan perpindahan wilayah kerja ke Kota Batam.

Daftar Nama Notaris Kota Batam

\begin{tabular}{|l|l|l|}
\hline No & Nama & Kedudukan \\
\hline 1 & Agny Yuanita Magdalen A Tambunan & Batam \\
\hline 2 & Agus Setyadi Hadisusilo & Batam \\
\hline 3 & Al Ayubi & Batam \\
\hline 4 & Analis Wida Delima Pandjaitan & Batam \\
\hline 5 & Andi Umi Pratiwi & Batam \\
\hline 6 & Andreas Timothy & Batam \\
\hline 7 & Andri Yuko & Batam \\
\hline 8 & Anita Mahdalena & Batam \\
\hline 9 & Anly Cenggana & Batam \\
\hline 10 & Antonius Adityo Ariwibowo & Batam \\
\hline 11 & Ariani Theresiana & Batam \\
\hline 12 & Arunee Oliva Depary & Batam \\
\hline
\end{tabular}

7 David Anthony, Teropong Gerakan Studi Hukum Kritis (Critical Legal Studies Movement) Terhadap Praktek Hukum Indonesia, 2008. 


\begin{tabular}{|c|c|c|}
\hline 13 & Aryanto Lie & Batam \\
\hline 14 & Azlan & Batam \\
\hline 15 & Bambang Muchsinanto & Batam \\
\hline 16 & Bambang Purwanto & Batam \\
\hline 17 & Basaina Parsaulian Siahaan & Batam \\
\hline 18 & Bun Hai & Batam \\
\hline 19 & Candy Desita Paramita Maria & Batam \\
\hline 20 & Carolina Mulyati & Batam \\
\hline 21 & Debora Ekawati Lukman Dadali & Batam \\
\hline 22 & Dessy Farhani & Batam \\
\hline 23 & Devi Ananji & Batam \\
\hline 24 & Dian Arianto & Batam \\
\hline 25 & Didik Ponco Sulistyono, & Batam \\
\hline 26 & Doddy Candra Eriawan & Batam \\
\hline 27 & Dr. Yudo Diharjo Lantanea & Batam \\
\hline 28 & Dwie Ponny Sulistiyan & Batam \\
\hline 29 & Dyah Sulistyoningtyas Kusumowardhani & Batam \\
\hline 30 & Edwin Timothy & Batam \\
\hline 31 & Elina Kartini & Batam \\
\hline 32 & Era Hendriyati Poerwasari & Batam \\
\hline 33 & Ernawati Thaher & Batam \\
\hline 34 & Erry Chandra & Batam \\
\hline 35 & Fajri Albastra & Batam \\
\hline 36 & Fenny & Batam \\
\hline 37 & Fuji Kadriah Zulaika & Batam \\
\hline 38 & Gema Fitria & Batam \\
\hline 39 & Gerard Ikhsan Iskandar & Batam \\
\hline 40 & H. Khairuddin Rasyid & Batam \\
\hline 41 & H. Mochamad Said & Batam \\
\hline 42 & H.Edison Muchlis & Batam \\
\hline 43 & Hanugerah & Batam \\
\hline 44 & Hasan & Batam \\
\hline 45 & Hatma Wigati Kartono & Batam \\
\hline 46 & Heidy Elke Kotandengan & Batam \\
\hline 47 & Hendra Prihatino & Batam \\
\hline 48 & Hendrialto & Batam \\
\hline 49 & Hentry Hynisiah & Batam \\
\hline 50 & Herry Ridwanto & Batam \\
\hline 51 & Heryani & Batam \\
\hline 52 & Hj. Tuti Rachmawati Lalo & Batam \\
\hline 53 & Indah Damayanti & Batam \\
\hline 54 & Indah Mulyanti & Batam \\
\hline 55 & Indra Ario Nasution & Batam \\
\hline 56 & Ir. Drs. H. Hendra Kusuma & Batam \\
\hline
\end{tabular}




\begin{tabular}{|c|c|c|}
\hline 57 & John Kelana Putra & Batam \\
\hline 58 & Johnson Wijaya & Batam \\
\hline 59 & Juli Cristie & Batam \\
\hline 60 & Jumala & Batam \\
\hline 61 & Justitia Ferryanto & Batam \\
\hline 62 & Karina Pramythasari & Batam \\
\hline 63 & Khoiron Syahid & Batam \\
\hline 64 & Kiki & Batam \\
\hline 65 & Krisnanti Soesilowati & Batam \\
\hline 66 & Lanni Ervina & Batam \\
\hline 67 & Mardiah Rasyid & Batam \\
\hline 68 & Maria Anastasia Halim & Batam \\
\hline 69 & Maria Hilaria Salim & Batam \\
\hline 70 & Maria Magdalena Ginting & Batam \\
\hline 71 & Maria Yosefina Neng & Batam \\
\hline 72 & Markus Gunawan & Batam \\
\hline 73 & Masda Nadapdap & Batam \\
\hline 74 & Mursyid Hidayat & Batam \\
\hline 75 & Najemah & Batam \\
\hline 76 & Nani Fitriyah & Batam \\
\hline 77 & Neldi & Batam \\
\hline 78 & Normayanti & Batam \\
\hline 79 & Nurhayati Suryasumirat & Batam \\
\hline 80 & Ny. Ria Adji Hendarto & Batam \\
\hline 81 & Pradep Kumar & Batam \\
\hline 82 & Rachmawati & Batam \\
\hline 83 & Raden Dian Nugroho Kusuma & Batam \\
\hline 84 & Reinward & Batam \\
\hline 85 & Rian Sugito & Batam \\
\hline 86 & Rida Marzuki & Batam \\
\hline 87 & Rio Zaldi & Batam \\
\hline 88 & Rita M.M.Simanungkalit & Batam \\
\hline 89 & Rita R.A. Simanjuntak & Batam \\
\hline 90 & Ritson & Batam \\
\hline 91 & Rivi Ariyanri & Batam \\
\hline 92 & Rudi Purba & Batam \\
\hline 93 & Ruth Widyastuti & Batam \\
\hline 94 & Sansan Antoni & Batam \\
\hline 95 & Septa Dorothe Undap & Batam \\
\hline 96 & Septa Suhendra & Batam \\
\hline 97 & Shinta Christiana Puspitasari & Batam \\
\hline 98 & Sigit Prihartono & Batam \\
\hline 99 & Sigit Sumantri & Batam \\
\hline 100 & Sinwar Widjono Oei & Batam \\
\hline
\end{tabular}




\begin{tabular}{|l|l|l|}
\hline 101 & Soehendro Gautama & Batam \\
\hline 102 & Sri Susilawati & Batam \\
\hline 103 & Syafrida Waty Tarigan & Batam \\
\hline 104 & Syaifudin & Batam \\
\hline 105 & Titik Aminah & Batam \\
\hline 106 & Titik Sulistyowati & Batam \\
\hline 107 & Ulfa Rudiasman & Batam \\
\hline 108 & Usman Koloay & Batam \\
\hline 109 & Valerie Andrea & Batam \\
\hline 110 & Vidia Cherria Chairunisa & Batam \\
\hline 111 & Vivin & Batam \\
\hline 112 & Wany Thamrin & Batam \\
\hline 113 & Wirlisman & Batam \\
\hline 114 & Wiwid Hanny Saputri & Batam \\
\hline 115 & Yanto Devira & Batam \\
\hline 116 & Yola Yostiwanti & Batam \\
\hline 117 & Yondri Darto & Batam \\
\hline 118 & Yosephina Hotma Vera & Batam \\
\hline 119 & Yulianistri & Batam \\
\hline 120 & Yulianti & Batam \\
\hline
\end{tabular}

\section{E. Kesimpulan}

Dari hasil penelitian ini dapat ditarik kesimpulan sebagai berikut :

1. Formasi pengangkatan Notaris ditetapkan berdasarkan :

a. Kegiatan dunia usaha

b. Jumlah penduduk; dan/atau

c. Rata - rata jumlah akta yang dibuat oleh dan/atau di hadapan Notaris setiap bulan.

2. Cara penentuan kategori daerah dalam penentuan daerah notaris di Kota Batam berdasarkan kuota dan kategori daerah, Notaris baru maupun yang telah bertugas tidak dapat secara langsung memilih tempat kedudukannya karena berdasarkan kuota yang ditetapkan oleh Menkumham Nomor 27 Tahun 2016 Dimana di dalam peraturan tersebut, Kota Batam masuk dalam Kategori Daerah C dengan solusi cara kategori daerah dalam penentuan daerah notaris di Kota Batam harusnya disesuaikan dengan jumlah motaris yang sudah ada, luas wilayah, jumlah penduduk, dan rata - rata aktivitas usaha di Kota Batam, dengan luas wilayah dan aktivitas perekonomian, karena saat ini sudah terdapat 120 notaris yang aktif di Kota Batam. 


\section{DAFTAR PUSTAKA}

\section{Buku}

Anshori, Abdul Ghofur, Lembaga Kenotariatan Indonesia, Yogyakarta, UII Press, 2009.

Amiruddin, Pengantar Metode Penelitian Hukum, Jakarta, PT. Raja Grafindo, 2010.

Anthony, David, "Teropong Gerakan Studi Hukum Kritis (Critical Legal Studies Movement) Terhadap Praktek Hukum Indonesia”, 2008.

Kie, Tan Thong Kie, Studi Notariat dan Serba-Serbi Praktek Notaris, Cetakan Kedua, Jakarta: PT. Ichtiar Baru van Hoeve., 2011.

Soekanto, Soerjono, Pengantar Penelitian Hukum, Jakarta, 2007.

Soemoatmodjo, Soetarjo, Apakah Notaris, PPAT, Pejabat Lelang, Yogyakarta, Liberty, 1986.

\section{Internet}

Wordpress, "Pengertian Penelitian Menurut Para Ahli", https://metodepenelitianhlw134a09.wordpress.com/2016/03/30/12pengertian-penelitian-menurut-para-ahli-lengkap/,diakses pada 22 Agustus 2019.

\section{Peraturan Perundang-undangan}

Undang-Undang Nomor 30 Tahun 2004 tentang Jabatan Notaris

Undang-Undang Nomor 39 Tahun 2008 tentang Kementerian Negara

Undang-Undang Nomor 2 Tahun 2014 tentang Perubahan Atas Undang-Undang Nomor 30 Tahun 2004 tentang Jabatan Notaris

Peraturan Presiden Republik Indonesia Nomor 7 Tahun 2015 tentang Organisasi Kementerian Negara

Peraturan Presiden Republik Indonesia Nomor 44 Tahun 2015 tentang Kementerian Hukum dan Hak Asasi Manusia

Peraturan Menteri Hukum dan Hak Asasi Manusia Republik Indonesia Nomor 25 Tahun 2014 tentang Syarat dan Tata Cara Pengangkatan, Perpindahan, Pemberhentian, dan Perpanjangan Masa Jabatan Notaris

Peraturan Menteri Hukum dan Hak Asasi Manusia Republik Indonesia Nomor 27 Tahun 2016 tentang Formasi Jabatan Notaris dan Penentuan Kategori Daerah 